\title{
Effect of surfactants in synthesis of $\mathrm{CsH}_{2} \mathrm{PO}_{4}$ as protonic conductive membrane
}

\author{
SORAYA HOSSEINI*, WAN RAMLI WAN DAUD, MARZIEH BADIEI ${ }^{\dagger}$ \\ ABDUL AMIR HASSAN KADHUM and ABU BAKAR MOHAMMAD \\ Institute of Fuel Cell, ${ }^{\dagger}$ Chemical Engineering Process, University Kebangsaan Malaysia, 43600 Bangi, Selangor, Malaysia
}

MS received 5 October 2009; revised 25 November 2009

\begin{abstract}
Cesium dihydrogen phosphate (CDP) powders were synthesized by cetyltrimethylammoniumbromide (CTAB), polyoxyethylene-polyoxypropylene (F-68) and mixture of both surfactants F-68: CTAB with two molar ratios 0.06 and 0.12 as surfactant solutions at room temperature. The synthesized $\mathrm{CsH}_{2} \mathrm{PO}_{4}$ is characterized by ICP, XRD, TEM, SEM, FT-IR, BET and IS techniques. Based on the width of the (011) XRD diffraction peak and BET measurement, the average size of nanoparticles was $\sim 10 \mathrm{~nm}$ in diameter, while the TEM images indicate smaller size than both techniques. The analysis reveals existence of $P$ and $C s$ with mole ratio $1.02 \pm 0.03$ which is compatible to molar ratio $\mathrm{CsH}_{2} \mathrm{PO}_{4}$ formula. The experimental results show that the conductivities increase in the order of $\mathrm{CDP}_{\mathrm{CTAB}}>\mathrm{CDP}_{(\mathrm{F}-68: \mathrm{CTAB}) 0.12}>\mathrm{CDP}_{(\mathrm{F}-68: \mathrm{CTAB}) 0.06}>\mathrm{CDP}_{\mathrm{F}-68}$. The sequence of increasing conductivity is in accordance with the ion exchange capacities of the samples that has direct proportional effect on the proton mobility of samples. Indeed CTAB as cationic surfactant shows the highest proton mobility in the as-obtained samples.
\end{abstract}

Keywords. $\quad \mathrm{CsH}_{2} \mathrm{PO}_{4}$; surfactant; nanoparticles; protonic conductivity.

\section{Introduction}

Extensive research of solid acids shows their utility because of the protonic conductivity properties and useful applications as electrolytes in fuel cells. The chemical composition is $\mathrm{M}_{\mathrm{a}} \mathrm{H}_{\mathrm{b}}\left(\mathrm{XO}_{4}\right)_{\mathrm{c}}$, where $\mathrm{M}=\mathrm{K}, \mathrm{Rb}, \mathrm{Cs}, \mathrm{NH}_{4}$, $\mathrm{X}=\mathrm{S}, \mathrm{Se}, \mathrm{P}$ and $\mathrm{a}, \mathrm{b}, \mathrm{c}$ are their respective stoichiometric coefficients (Baranov 2003). Cesium dihydrogen phosphate (CDP), or $\mathrm{CsH}_{2} \mathrm{PO}_{4}$, is a member of this group of solid acids, which is built from the discrete $\mathrm{PO}_{4}$ tetrahedral connected by $\mathrm{O}-\mathrm{H}$... O hydrogen bonds through the electrostatic interaction of the cesium cation. $\mathrm{CsH}_{2} \mathrm{PO}_{4}$ undergoes a three phase transition; the first is the ferroelectric phase transition at $T=154 \mathrm{~K}$ with space group $P 2_{1}$ and completely ordered hydrogen bonds transform. Below this temperature, protons in the shorter hydrogen bond $(2.48 \AA)$ are ordered to the oxygen atom of $\mathrm{PO}_{4}$ group, disturbing the $\mathrm{PO}_{4}$ ion configuration and lowering its symmetry (Kennedy and Nelmes 1980; Deguchi et al 1982).

At room temperature or paraelectric phase, $\mathrm{CsH}_{2} \mathrm{PO}_{4}$ is monoclinic with space group $P 2_{1} / m$ and two formula units per unit cell $(Z=2)$ and partly disordered hydrogen bond (JCPDS-ICDD 1995). Morever, it has been reported that $\mathrm{CsH}_{2} \mathrm{PO}_{4}$ undergoes a phase transition at $504 \mathrm{~K}$ and space group $P m 3 m$ symmetry (cubic) with

*Author for correspondence (soraya@eng.ukm.my) disordered hydrogen bond which is the "superprotonic phase transition'. The superprotonic phase transition is distinguished by rapid proton transfer on the hydrogen bonds and the liberation of oxy-anion $\left(\mathrm{PO}_{4}\right)$ at $504 \mathrm{~K}$ (Bronowska 2001; Boysen et al 2003; Otomo et al 2003). The proton conductivity rises due to superprotonic phase transition from two to three orders of magnitude, reaching values as high as $10^{-2}-10^{-3} \Omega^{-1} \mathrm{~cm}^{-1}$ (Baranov et al 1982; Haile et al 2001). A study was undertaken to investigate the CDP morphology, using methanol and polyols by Kim et al (2006) which showed that samples with spherical morphology and smaller particle size produce relatively higher values of conductivity. The synthesis of CDP employs various methods such as solvent evaporation and the addition of a second solvent to reduce the solubility of the solute. A new method for the preparation of CDP is the surfactants method with reduction in particles size. In this paper, the surfactants method is used to synthesize $\mathrm{CsH}_{2} \mathrm{PO}_{4}$ nanoparticles by cationic surfactant as CTAB, non-ionic surfactant F-68 and the surfactants mixture (F-68:CTAB) with two molar ratios 0.06 and $0 \cdot 12$. The micelle concentration of CTAB determines the shape of the nanoparticles. CTAB can generate different morphology using concentrations above and below critical micelle concentration (CMC). It forms spherical micelles above the CMC (0.00001 mole in solvent) and produces rod shape micelles below the CMC (Olivera et al 2006; Jun and Ki 2009). The conductivity also depends 
on the morphology and degree of crystallinity (McCall et al 1989).

\section{Experimental}

The synthesis of $\mathrm{CsH}_{2} \mathrm{PO}_{4}$ nanoparticles was achieved using a stoichiometric amount of cesium carbonate $\mathrm{Cs}_{2} \mathrm{CO}_{3}$ (99.99\% Aldrich), orthophosphoric acid $\mathrm{H}_{3} \mathrm{PO}_{4}$ (85\%wt Aldrich) and two surfactants Cetyltrimethylammoniumbromide (99\% SIGMA), polyoxyethelen-polyoxypropylene (Pluronic, F-68 SIGMA) and a mixture of both surfactants (F-68:CATB) with two molar ratios 0.06 and $0 \cdot 12$. The reaction is follows:

$$
\mathrm{Cs}_{2} \mathrm{CO}_{3}+2 \mathrm{H}_{3} \mathrm{PO}_{4} \rightarrow 2 \mathrm{CsH}_{2} \mathrm{PO}_{4}+\mathrm{CO}_{2}+\mathrm{H}_{2} \mathrm{O} \text {. }
$$

Samples of different sized nanaoparticle were prepared with CTAB, F-68 (F-68: CTAB) $)_{0.06}$ and (F-68: $\mathrm{CTAB})_{0.012}$. For CDP preparation, measured amount of $\mathrm{Cs}_{2} \mathrm{CO}_{3}$ was dissolved in distilled water. The surfactant solution was separately prepared using CTAB, F-68 (F68: $\mathrm{CTAB})_{0.06},(\mathrm{~F}-68 \text { : CTAB })_{0.12}$ and ethanol (99.99\%) with vigorous stirring (figure 1). After $20 \mathrm{~min}$, when all the surfactants have dissolved in ethanol, the solution becomes clear and then it was added to the $\mathrm{Cs}_{2} \mathrm{CO}_{3}$ aqueous solution with continuous stirring at room temperature for $10 \mathrm{~min}$. A measured amount of $\mathrm{H}_{3} \mathrm{PO}_{4}$ was added, drop-wise, into the resulting solution under stirring for $1 \mathrm{~h}$. Subsequently, a white precipitate of $\mathrm{CsH}_{2} \mathrm{PO}_{4}$ powder is formed. The as-prepared sample was dried at $130^{\circ} \mathrm{C}$ overnight and then collected as dry powder. The first endothermic peak of nanoparticles was observed, by DSC and TGA analyses in the range of $233-244^{\circ} \mathrm{C}$ with weight loss of more than 3\% (Hosseini et al 2009). For this reason and to prevent side productions of $\mathrm{CsH}_{2} \mathrm{P}_{2} \mathrm{O}_{7}$ and

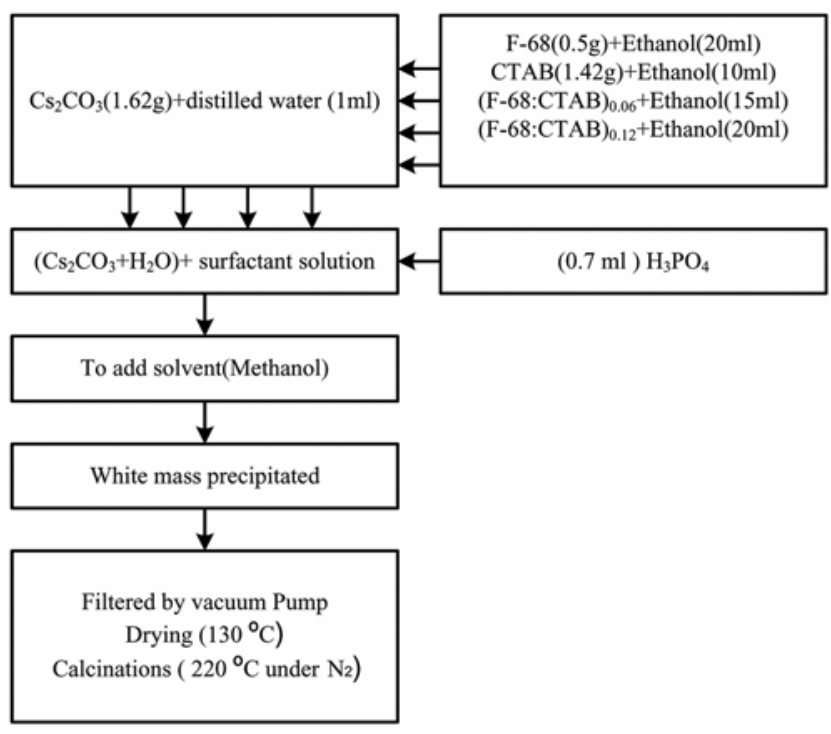

Figure 1. Flow chart for the synthesis of $\mathrm{CsH}_{2} \mathrm{PO}_{4}$ nanoparticles by the surfactants.
$\mathrm{CsPO}_{3}$, after sufficient drying, the white precipitate was calcinated at $220^{\circ} \mathrm{C}$ for $8 \mathrm{~h}$ under $\mathrm{N}_{2}$ gas. Impedance was measured using a Solarton 200 over the frequency range $0.01 \mathrm{~Hz}-1 \mathrm{MHz}$, a controller of temperature West Model 6100 , a furnace with standard thermocouple ${ }^{\circ} \mathrm{C}$ under $\mathrm{Ar} / \mathrm{H}_{2} \mathrm{O}\left(\mathrm{Ar}: \mathrm{H}_{2} \mathrm{O}=0.9: 0 \cdot 1\right)$. The samples were pressed under a pressure of $191 \mathrm{~kg} \mathrm{~cm}^{-2}$ to form pellets of diameter and thickness, $10 \mathrm{~mm}$ and $2 \mathrm{~mm}$ respectively. Both sides of the pellets were coated with carbon paste using graphite. The pellet was sandwiched between two silver holders and connected to impedance analyzer. The real $Z^{\prime}$ and the imaginary $Z^{\prime \prime}$ parts of the impedance were measured between 30 and $260^{\circ} \mathrm{C}$ for intervals of $20^{\circ} \mathrm{C}$. Data was analysed using commercial software package, ZView2 to calculate the proton conductivity.

\section{Analytical instruments}

Particle structure was identified using a diffractometer (Bruker D8 Advance) with $\mathrm{CuK} \alpha_{1}$ radiation. The particle size and conglomeration state were recorded using transmission electron microscopy (Philips CM-12) at an accelerating voltage of $20 \mathrm{kV}$. The aggregates of CDP were rinsed several times with $95 \%$ ethanol. After employing ultrasonic on the samples for $5 \mathrm{~min}$ at $20^{\circ} \mathrm{C}$, the suspension was dripped onto a small cupper grid and air-dried for measuring the size. Scanning electron microscopy (SEM) was carried out on an electron microscope system (LEO 1450VP) attached to EDX analyzer. IR spectrum was recorded on FT-IR spectrophotometer (Nicolet 6700) in the range of $400-4000 \mathrm{~cm}^{-1}$. Sample was prepared by finely dispersing powder material on a $\mathrm{KBr}$ carrier. The specific surface area of the calcined powders was measured by BET analysis (Ami 2000) using $\mathrm{N}_{2}$ in a three step adsorption-desorption process. Proton conductivity was measured by impedance spectroscopy technique, using a Solarton 200 over the frequency range $0.01 \mathrm{~Hz}-1 \mathrm{MHz}$, in the temperature range of $30-260^{\circ} \mathrm{C}$.

\section{Results and discussion}

Nucleation and the growth mechanism strongly influence particle morphology. The presence of impurities, especially macromolecular impurities such as polymers (Manna et al 2000) or surfactants can alter the shape of the growing crystal. In view of this, surfactants CTAB, F-68 and mixture of F-68: CTAB were used to yield smaller particles and different particle morphology.

\subsection{ICP and XRD analysis}

$\mathrm{CsH}_{2} \mathrm{PO}_{4}$ nanoparticles were prepared as discussed in the experimental section. Different sizes of nanoparticles were obtained by changing surfactant type and the molar concentration of (F-68: CTAB) solution. 
In order to evaluate the mole ratio $\mathrm{Cs} / \mathrm{P}$ of the samples, analysis of elements was carried out in the five the samples. The values of $\mathrm{P}$ and $\mathrm{Cs}$ are reported for both the group of samples (using surfactant and without surfactant). Clearly, the value of

$$
\frac{\mu \mathrm{g} \text { (component) }}{\mathrm{g}\left(\mathrm{CsH}_{2} \mathrm{PO}_{4}\right)}
$$

in the sample (without surfactant) is more than the other samples. This difference is due to the calcination process during the removal of the template (due to surfactants) around the particle by heat. The calcination process results in the loss of some $\mathrm{P}$ and $\mathrm{Cs}$ in these compounds. The mole ratio of $\mathrm{Cs} / \mathrm{P}$ is $1.02 \pm 0.03$ which is compatible to the mole ratio of $\mathrm{CsH}_{2} \mathrm{PO}_{4}$ formula.

The structures of different sizes of nanoparticles namely $\mathrm{CDP}_{\mathrm{CTAB}}, \quad \mathrm{CDP}_{\mathrm{F}-68}, \quad \mathrm{CDP}_{(\mathrm{F}-68: \mathrm{CTAB}) 0.06}, \quad \mathrm{CDP}_{(\mathrm{F}-68:} \mathrm{CTAB)0.12}$ were studied at room temperature using $\mathrm{X}$-ray diffraction which were measured in the $2 \cdot 3^{\circ} \leq \theta \leq 60^{\circ}$ range on a Bruker AXS D8 Advance device operated at $40 \mathrm{kV}, 40 \mathrm{~mA}$ with $\mathrm{CuK} \alpha$ radiation $(\lambda=1.5405 \AA)$ at step size of $2 \theta=0.02^{\circ}$ and a fixed counting time of $1 \mathrm{~s} / \mathrm{step}$ and analyzed with a EVA software. Cell parameters were determined by least-squares of all reflections in the measured $2 \theta$ range as listed in table 1 . The refinement leads to rather good agreement between the experimental and calculated XRD patterns and yields acceptable reliability factors: $R$, $R_{\text {exp }}, R_{\text {wp }}$ and GOF (Rietveld 1969; Larson and Von Dreele 2000; Kojitani et al 2005). In Rietveld analysis, a least squares method is used to obtain the best possible fit between the observed and simulated powder diffraction patterns. Residual of fitting $\left(I_{\mathrm{o}}-I_{c}\right)$ between observed $\left(I_{\mathrm{o}}\right)$ and calculated $\left(I_{\mathrm{c}}\right)$ intensities of each fitting is plotted under respective patterns as shown in figure 2 . The fitting quality is relatively good and varies between 1.02 and 1.7 .

All the diffraction peaks in figures $2 \mathrm{a}, \mathrm{b}, \mathrm{d}$, e index well to the monoclinic phase structure of $\mathrm{CsH}_{2} \mathrm{PO}_{4}$ (JCPDS 01-084-0122) (Matsunaga et al 1980). All the diffraction peaks in figure $2 \mathrm{c}$ index well to the orthorhombic phase structure of $\mathrm{CsH}_{2} \mathrm{PO}_{4}$ (JCPDS 01-0832191) (Rashkovich 1991). The maximum peak located at $24.5^{\circ}$ corresponds to the (011) plane with the other principal peaks corresponding to the planes (110), (001), $(020),(021)$ and $(220)$ located at $17^{\circ}, 19^{\circ}, 30^{\circ}, 34.5^{\circ}$ and $38^{\circ}$, respectively. Nanoparticle sizes were calculated based on the half-peak width of the diffraction peak at miller index $\left(011,2 \theta=24 \cdot 5^{\circ}\right)$ using the Scherrer's equation. The average crystallite diameter, $d$, was estimated from the broadening of the XRD peak widths by the Scherrer formula

$$
D=\frac{K \lambda}{\beta \cos \theta},
$$

where $\lambda$ is the wavelength of the radiation, $\beta$ is the integral width of the Bragg reflection at $2 \theta$, and $K$ is the
Scherrer constant $(0.93)$ which depends on factors such as the geometry of the crystallites (Burton et al 2009). Figure 2 shows XRD patterns for the CDP samples prepared with and without surfactants. The peaks in the $\mathrm{CDP}_{\text {evaporation }}$ pattern were noticeably sharper, indicating larger, more crystalline particles than in the $\mathrm{CDP}_{\text {surfactant }}$.

Miller index for the observed peaks are given figure 2e, wherein some differences are noticed in the Miller indexes for samples that directly influence morphology of the particles. The growth and morphology of crystals depend on Miller index planes. The effect of methanol solution on crystal morphology suppresses crystal growth by extracting solvent water from solution and adsorbing onto the crystal surface; adsorption on to particular sites of crystallites change the expanded capacity of every plane (Dongli et al 2005). EDX analyses showed no impurity yield during synthesis.

\subsection{BET and TEM analysis}

The specific surface area of samples was characterized by $\mathrm{N}_{2}$ adsorption at liquid nitrogen temperature using an Ami 2000 instrument. Prior to analysis, the samples were placed in vacuum at $200^{\circ} \mathrm{C}$ for $2 \mathrm{~h}$ to remove the surface adsorbed species. The data were analysed according to

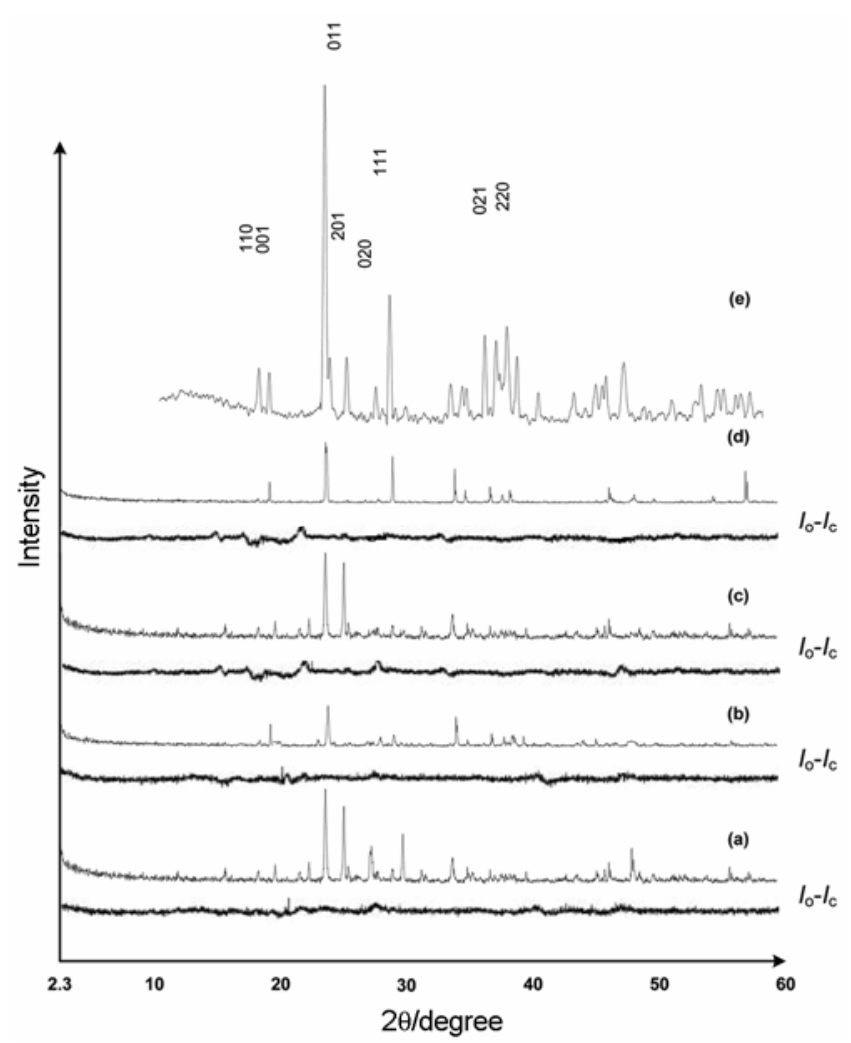

Figure 2. XRD patterns of the powder $\mathrm{CDP}$, using (a) $\mathrm{CDP}_{\mathrm{CTAB}}$, (b) $\mathrm{CDP}_{\mathrm{F}-68}$, (c) $\mathrm{CDP}_{\text {(F-68:CTAB)0.06, }}$ (d) $\mathrm{CDP}(\mathrm{F}-68: \mathrm{CTAB}) 0.12$ and (e) $\mathrm{CDP}$ (without surfactant). 
Table 1. Structural parameters of the CDP samples at room temperature.

\begin{tabular}{lccccc}
\hline Parameters & $\mathrm{CDP}_{[17]}$ & $\mathrm{CDP}_{\mathrm{F}-68}$ & $\mathrm{CDP}_{(\mathrm{F}-68: \mathrm{CTAB}) 0.06}$ & $\mathrm{CDP}_{(\mathrm{F}-68: \mathrm{CTAB}) 0 \cdot 12}$ & $\mathrm{CDP}_{\mathrm{CTAB}}$ \\
\hline$\alpha$ & $7 \cdot 912$ & $7 \cdot 997$ & $4 \cdot 872$ & $7 \cdot 995$ & $7 \cdot 907$ \\
$b$ & $6 \cdot 386$ & $6 \cdot 383$ & $6 \cdot 368$ & $6 \cdot 382$ & $6 \cdot 386$ \\
$c$ & $4 \cdot 88$ & $4 \cdot 88$ & $15 \cdot 049$ & $4 \cdot 88$ & $4 \cdot 88$ \\
$\beta$ & $107 \cdot 73$ & $107 \cdot 73$ & $90 \cdot 22$ & $107 \cdot 75$ & $107 \cdot 71$ \\
$z$ & 2 & 4 & 4 & 2 & 2 \\
space & $P 2_{1} / m$ & $C 2 / c$ & $B 2{ }_{1} / m$ & $P 2_{1} / m$ & $P 2_{1} / m$ \\
GOF & & $1 \cdot 105$ & $1 \cdot 127$ & $1 \cdot 153$ & $1 \cdot 165$ \\
$R$ & & $4 \cdot 35 \%$ & $5 \cdot 32 \%$ & $6 \cdot 12 \%$ & $5 \cdot 15 \%$ \\
$R_{\text {wp }}$ & & $7 \cdot 94 \%$ & $9 \cdot 22 \%$ & $8 \cdot 29 \%$ & $8 \cdot 34 \%$ \\
$R_{\exp }$ & & $6 \cdot 08 \%$ & $7 \cdot 54 \%$ & $7 \cdot 34 \%$ & $6 \cdot 17 \%$ \\
\hline
\end{tabular}

the Brunauer-Emmet-Teller (BET) analysis based on the Langmuir equation. The average particle size can be estimated by assuming that all particles have the same shape and size. The average particle diameter, $D$, is given by (Hammes et al 2008)

$$
D=\frac{6}{S_{\mathrm{sp}} \cdot \rho_{\mathrm{p}}},
$$

where $S_{\mathrm{sp}}$ and $\rho_{\mathrm{P}}$ are the specific surface area per unit mass of the sample and the true density, respectively. The nanoparticle density was calculated by pycnometer using dimethylformamide (DMF) as listed in table 2.

Figure 3 shows the TEM micrograph of $\mathrm{CDP}_{(\mathrm{F}-68: \mathrm{CTAB}) 0.06 \text {. }}$ The particle size is determined by transmission electron microscope (TEM) images that are based on an automated image analysis. The normal size distribution of the particles calculated by mathematical equations comprising of the parameters, mean $(\zeta)$, standard deviation $(v)$ and nanoparticle size $(x)$ is as follows:

$$
F(x)=\frac{\mathrm{e}^{\frac{-(x-\varsigma)^{2}}{2 v^{2}}}}{\sqrt{2 \pi v^{2}}},
$$

According to TEM analysis and the normal size distribution plots, the smallest size of particles is generated by surfactant F-68 as shown in table 2. It is usual the TEM analysis to yield average particle sizes biased toward smaller sizes, since the method of sample preparation often uses a TEM grid which selects (filters) only the smallest particles deposited from solution, then two methods of particle size measurement was performed by XRD and BET measurement. The comparison between these techniques is listed in table 2. The obtained particle sizes from the XRD were in the range $10 \mathrm{~nm}$, in good agreement with those calculated from BET analysis.

\subsection{IS and FTIR analysis}

The protonic conductivity of $\mathrm{CsH}_{2} \mathrm{PO}_{4}$ nanoparticles is performed by electrochemical impedance spectroscopy technique in the frequency range $0.01 \mathrm{~Hz}$ to $1 \mathrm{MHz}$ for samples $\mathrm{CDP}_{\mathrm{F}-68}, \mathrm{CDP}_{\mathrm{CTAB}}, \mathrm{CDP}_{(\mathrm{F}-68: \mathrm{CTAB}) 0.06}$ and $\mathrm{CDP}_{(\mathrm{F}-}$ 68:CTAB)0.12. The impedance spectroscopy of $\mathrm{CsH}_{2} \mathrm{PO}_{4}$ nanoparticles are represented in Nyquist diagram in rang of temperature $30-260^{\circ} \mathrm{C}$. Typical impedance spectra were obtained below superprotonic phase $\left(210^{\circ} \mathrm{C}\right)$, at superprotonic phase $\left(230^{\circ} \mathrm{C}\right)$ and above superprotonic phase $\left(260^{\circ} \mathrm{C}\right)$. Good agreement was observed between the experimental and the equivalent circuits (using Zview2) (Hosseini et al 2011). The relative error between the experimental and calculated spectra is less than $3 \%$. Due to the change in relative contribution of bulk electrolyte and interface to the total impedance, the spectra changed remarkably below and above the superprotonic transition temperature as shown in figure 4.

Temperature dependencies of the protonic conductivity obtained using impedance measurement data by the classical Arrhenius equation are presented in figure 5.

$$
\sigma=\frac{A}{R} \exp \left(\frac{-E}{K T}\right)
$$

The Arrhenius plot consists of two straight lines of different slopes at the regions of low and high temperatures, respectively. The shape of the plot has been generally attributed to the existence of distinct mechanisms, involving of two different activation energies, each one dominating at a particular range of temperatures. $\mathrm{CsH}_{2} \mathrm{PO}_{4}$ undergoes a thermal decomposition at $149^{\circ} \mathrm{C}$ which, much like the transition at $230^{\circ} \mathrm{C}$, gives rise to an increase in conductivity (Ortiz et al 1999a, b). The non-linearity of Arrhenius plot resulted due to the different thermal behaviors of $\mathrm{CsH}_{2} \mathrm{PO}_{4}$ and the different activation energies.

The conductivities of the monoclinic phases increase sharply at the superprotonic transition temperatures, which coincide with the thermal events observed by DSC analysis. The impedance analysis indicate increasing conductivity as sequential $\left.\mathrm{CDP}_{\mathrm{CTAB}}>\mathrm{CDP}_{(\mathrm{F}-68:} \mathrm{CTAB}\right) 0.012_{2}>$ $\mathrm{CDP}_{(\mathrm{F}-68: \mathrm{CTAB}) 0.06}>\mathrm{CDP}_{\mathrm{F}-68}$. As seen in figure 5, the maximum jump in protonic conductivity is noticed in the range $210-230^{\circ} \mathrm{C}$ wherein upon heating above $230^{\circ} \mathrm{C}$, the protonic conductivity decrease in samples 
Table 2. Average particle size, ion exchange capacity and density of nanoparticles.

\begin{tabular}{|c|c|c|c|c|c|}
\hline Samples & TEM (nm) & $\mathrm{XRD}(\mathrm{nm})$ & $\mathrm{BET}(\mathrm{nm})$ & $\begin{array}{l}\text { Ion exchange capacity } \\
\qquad\left(\mathrm{mmol} \mathrm{g}^{-1}\right)\end{array}$ & $\begin{array}{l}\text { Density } \\
\left(\mathrm{g} \mathrm{cm}^{-3}\right)\end{array}$ \\
\hline $\mathrm{CDP}_{\mathrm{CTAB}}$ & $3.7 \pm 0.488$ & $10 \cdot 3 \pm 0 \cdot 45$ & $11 \cdot 35 \pm 0.48$ & $1.09 \pm 0.02$ & $3 \cdot 53 \pm 0 \cdot 13$ \\
\hline $\mathrm{CDP}_{\mathrm{F}-68}$ & $2.66 \pm 0.89$ & $6 \cdot 85 \pm 0.87$ & $8.71 \pm 0.69$ & $0.75 \pm 0.03$ & $3 \cdot 42 \pm 0 \cdot 2$ \\
\hline $\mathrm{CDP}(\mathrm{F}-68: \mathrm{CTAB})_{0.06}$ & $3 \cdot 5 \pm 0 \cdot 56$ & $11.23 \pm 0.54$ & $10 \cdot 81 \pm 0.45$ & $0.89 \pm 0.02$ & $3 \cdot 37 \pm 0 \cdot 18$ \\
\hline $\mathrm{CDP}(\mathrm{F}-68: \mathrm{CTAB})_{0.12}$ & $4.89 \pm 0.27$ & $12 \cdot 37 \pm 0 \cdot 69$ & $11 \cdot 88 \pm 0.21$ & $0.91 \pm 0.04$ & $3 \cdot 49 \pm 0 \cdot 11$ \\
\hline
\end{tabular}

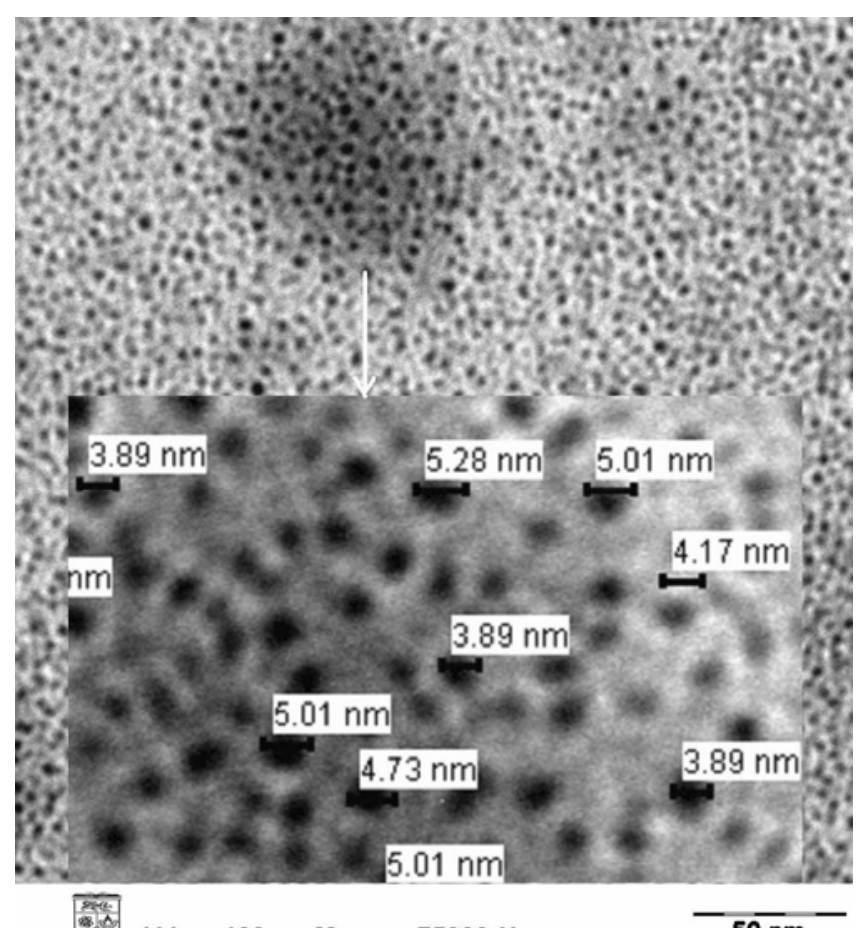

$k V=100 \quad M a g=75000 x$

Figure 3. TEM patterns of $\mathrm{CDP}_{(\mathrm{F}-68: \mathrm{CTAB}) 0 \cdot 06 \text {. }}$

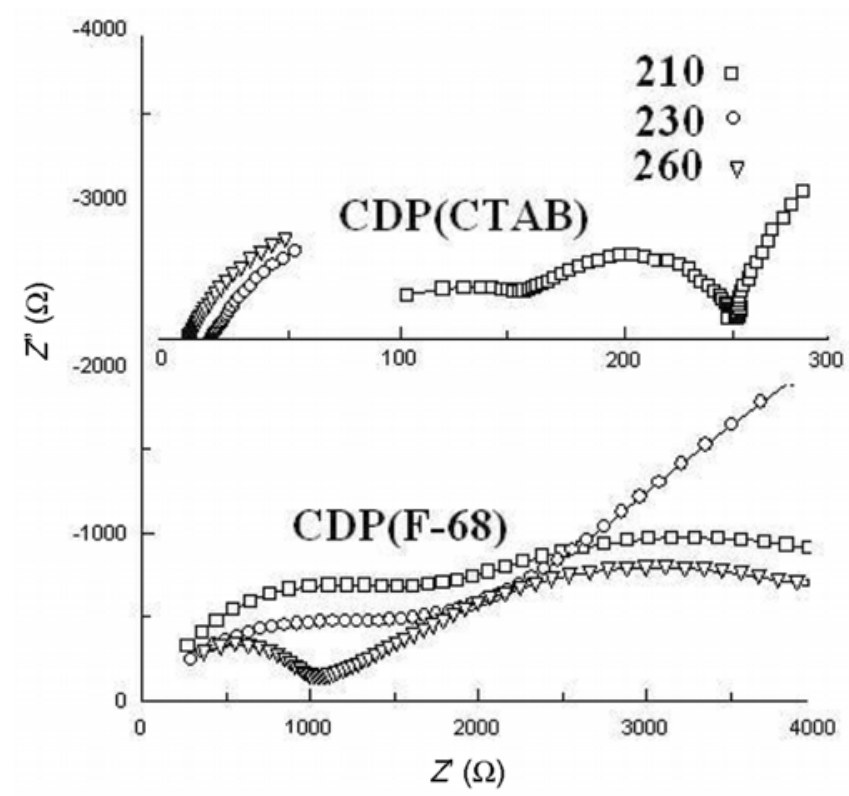

Figure 4. Nyquist plots of two samples $\mathrm{CDP}_{\mathrm{CTAB}}$ and $\mathrm{CDP}_{(\mathrm{F}-68: \mathrm{CTAB}) 0.06 \text {. }}$

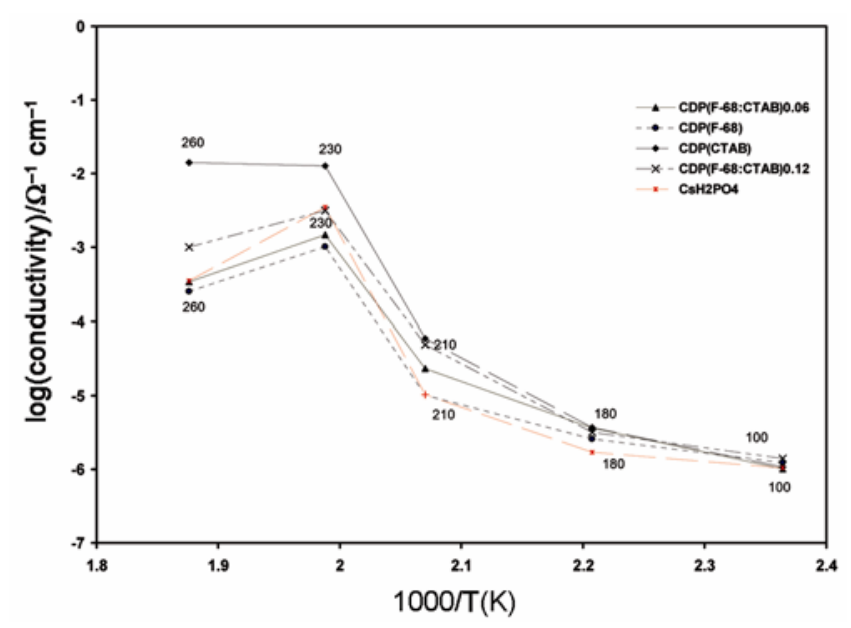

Figure 5. A comparative temperature dependence of the conductivity CDP samples.

$\mathrm{CDP}_{\text {(F-68:CTAB)0.012, }}, \mathrm{CDP}_{\text {(F-68:CTAB)0.06 }}$ and $\mathrm{CDP}_{\mathrm{F}-68}$ except in $\mathrm{CDP}_{\mathrm{CTAB}}$ where there is a slight increase above the phase transition temperature. Proton conductivities of the nanparticles are consistent with their ion exchange capacity (IEC) values, and are well represented by Arrhenius equation (Daiko et al 2007). Among the CDP samples, CDPCTAB showed the highest IEC value. This shows the direct proportional effect of IEC on the proton mobility.

Solid acids show high protonic conductivity at superprotonic phase transition accompanied by breaking of the hydrogen bonds, due to the rotational motion of $\mathrm{XO}_{4}$ tetrahedrons. In order to confirm the presence of hydrogen bonds and anions $\mathrm{PO}_{4}^{-3}$ in the crystal lattice, infrared absorption spectra of the samples was taken in the range of $4000-400 \mathrm{~cm}^{-1}$, as shown in figure 6 . The bands were assigned to the paraelectric phase of $\mathrm{CsH}_{2} \mathrm{PO}_{4}$ nanoparticles (stable at room temperature). The IR spectrum consists of a number of well separated groups of bands; $3600-1300 \mathrm{~cm}^{-1}$ (high frequency $\mathrm{H}$ modes), 1300$800 \mathrm{~cm}^{-1}$ (stretching $\mathrm{P}-\mathrm{O}$ and bending $\mathrm{P}-\mathrm{OH}$ modes) and $800-400 \mathrm{~cm}^{-1}$ (stretching OPO modes and $\mathrm{Cs} . . \mathrm{O}$ ) (Le Calve et al 1989; Romain and Novak 1991; Hubert et al 1995). The $\mathrm{ABC}$ structure of the $v(\mathrm{OH})$ stretching vibrations is observed for many solid acids where the stretching $\mathrm{OH}$... O hydrogen bonds reveal centers of lines at 2800,2500 and $1650 \mathrm{~cm}^{-1}$ (Kalevitchayb et al 1995). For each $\mathrm{OH}$ bond, the $\mathrm{O}-\mathrm{H}$ motions are known as $v$ $(\mathrm{OH}), \delta(\mathrm{OH})$ and $\gamma(\mathrm{OH})$ i.e. stretching $\mathrm{O}-\mathrm{H}$, in plane 


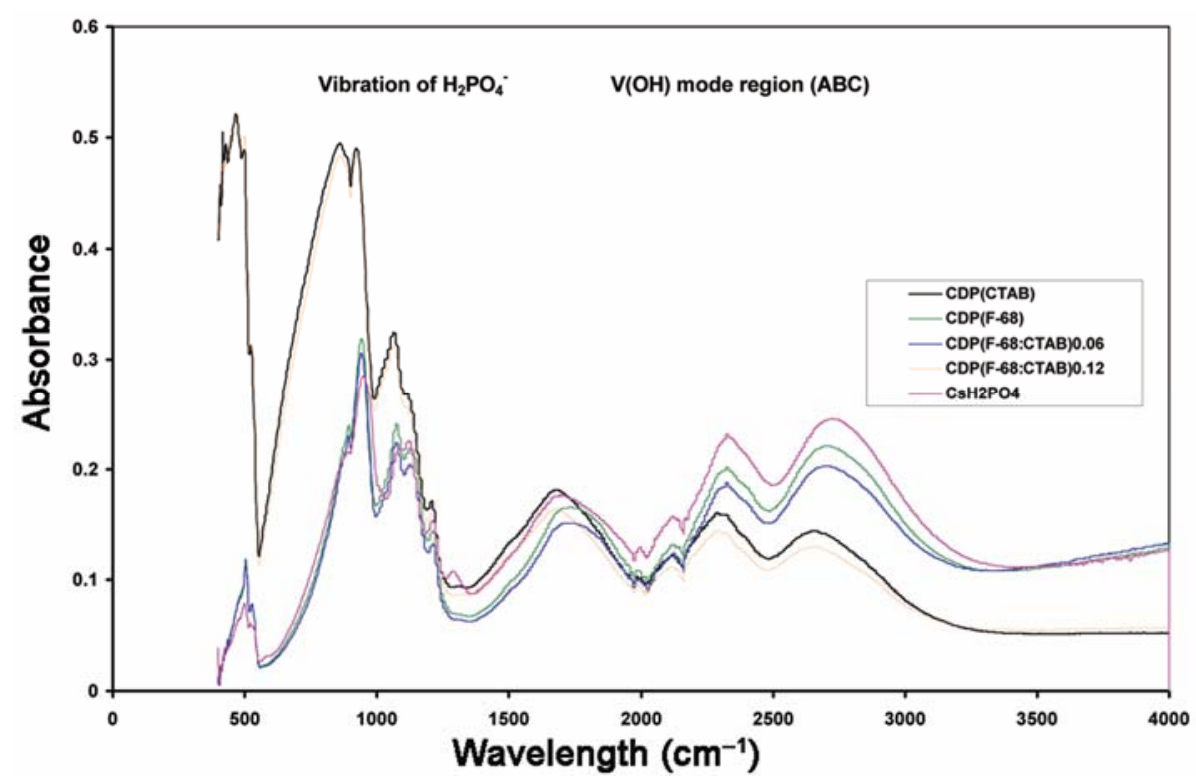

Figure 6. IR spectra of the samples CDP at ambient temperature $\left(400-4000 \mathrm{~cm}^{-1}\right)$.

and out-of-plane bending $\mathrm{P}-\mathrm{O}-\mathrm{H}$ vibration, respectively (Koleva et al 2009). Due to the Fermi resonance between $v(\mathrm{OH})$ and overtones of the deformation modes $\delta(\mathrm{OH})$ and $\gamma(\mathrm{OH})$ appear as the $\mathrm{ABC}$ structure. The phenomenon was noticed in some solid acids that can be compatible with the ABC structure (Toupry and Poulet 1981; Kalevich et al 1993). The well separated peaks of CDP nanoparticles at 2650, 2300 and $1650 \mathrm{~cm}^{-1}$ in the IR spectra can be assigned to the $\mathrm{ABC}$ bonds of $\mathrm{OH}$. The strong absorption of the samples in the region $900-1200 \mathrm{~cm}^{-1}$ in the IR spectra can undoubtedly be assigned to the components of the $\mathrm{PO}_{4}$ while the four bands at 1185, 1140, 1070 an $940 \mathrm{~cm}^{-1}$ are attributed to the $\mathrm{P}-\mathrm{O}$ stretching modes in the $\mathrm{H}_{2} \mathrm{PO}_{4}$ - anion that is compatible to reported data (Koleva et al 2009). The generated bond due to $\mathrm{Cs}$... O-H is observed at $490 \mathrm{~cm}^{-1}$. According to Beer's law measured absorbance shows a linear relationship with concentration of impurity, absorptivity of a particular bond and thickness of sample (Ross Boyle 2005). The increase in absorbance values of samples $\mathrm{CDP}_{\mathrm{CTAB}}$ and $\mathrm{CDP}_{(\mathrm{F}-68: \mathrm{CATB}) 0.12}$ can be due to the impurity concentration.

\section{Conclusions}

It is possible to produce $\mathrm{CsH}_{2} \mathrm{PO}_{4}$ nanoparticles of different sizes using the chemical method by surfactants. The XRD, TEM and BET data were obtained to confirm nanosize of these materials. It is also observed that the particle size depends on molar concentration of the surfactant solution and type of surfactant. The measured proton conductivity indicates the increasing as sequential $\mathrm{CDP}_{\mathrm{CTAB}}>$ $\mathrm{CDP}_{(\mathrm{F}-68: \mathrm{CTAB}) 0.012}>\mathrm{CDP}_{(\mathrm{F}-68: \mathrm{CTAB}) 0.06}>\mathrm{CDP}_{\mathrm{F}-68}$ respec- tively. Among the samples, $\mathrm{CDP}_{\mathrm{CTAB}}$ had the highest value of proton mobility.

\section{Acknowledgement}

The authors appreciate the financial support of the IRPA02-02-02-0006 PR0023/11-08.

\section{References}

Baranov A I 2003 Cryst. Rep. 461012

Baranov A I, Shuvalov L A and Shchagina N M 1982 JETP Lett. 36459

Boysen D A, Haile S M, Liu H and Secco R A 2003 Chem. Mat. 15727

Bronowska W 2001 J. Chem. Phys. 114611

Burton A W, Ong K, Rea Th and Chan I Y 2009 Micro. Meso. Mat. 11775

Daiko Y, Katagiri K, Ogura K, Sakai M and Matsuda A 2007 Solid State Ionic 178601

Deguchi K, Nakamura E and Okaue E 1982 J Phys. Soc. 51 3569

Dongli Xu, Dongfeng X and Henryk R 2005 J. Mol. Struct. 740 37

Jun Y and Ki Zh 2009 Technology Application DOI CNKI:SUN:HCSY.0.2009-03-009

Haile S A, Boysen D A, Chisholm C R I and Merie R B 2001 Nature 410910

Hammes K, Smernik R J, Skjemstad J O and Schmidtt W 2008 Appl. Geoch. 232113

Hosseini S, Mohamad A B, Khadum A H and Wan Doud W R 2009 J. Therm. Anal. Cal. Doi: 10.1007/s10973-009-0132-2

Hosseini S, Homaeei M, Mohamad A B, Malekbala M R and Khadhum A A H 2011 Phys. B: Condens. Matter 406 1689 
Hubert J, Jayakumar V S and Aruldhas G 1995 J. Solid State Chem. 120343

JCPDS-ICDD 1995 Database 35746

Kalevich N I, Maljarevich AM and Posledovich MR 1993 Bull. Russ. Chem. Phys. 121015

Kalevich N I, Posledovich M R and Rodin S V 1993 Bull. Russ. Acad. Sci. Phys. 57385

Kalevitchayb N I, Arnscheidtb B, Pelzlb J and Rodina S V 1995 J. Mol. Struct. 348361

Kennedy N S J and Nelmes R J 1980 J. Phys. C13 4841

Kim J, Ahn Y S, Ruth MI and Park C W 2006 J. Power Sources 163107

Kojitani H, Kido M and Akaogi M 2005 Phys. Chem. Miner. 32 290

Koleva V, Stefov V, Cahil A, Najdoski M, Šoptrajanov B, Engelen B and Lutz HD 2009 J. Mol. Struct. 917 117

Larson A C and Von Dreele R B 2000 Los Alamos National Laboratory Report LAUR 86-748, USA

Larson A C and Von Dreele R B 2006 General structure analysis system technical manual LANSCE, MS-H805 2000 (LAUR: Los Almos National University) Vol. 86 p. 66
Le Calve N, Romain F, Limage M H and Novak A 1989 J. Mol. Struct. 200131

Manna L, Scher E C and Alvisatos A P 2000 J. Am. Chem. Soc. 12212700

Matsunaga H, Itoh K and Nakamura E 1980 J. Phys. Soc. Jpn. 482011

McCall R P, Ginder J M, Roe M G, Asturias G E, Scherr E M, Macdiarmid A G and Epstein A J 1989 Phys. Rev. B39 10174 Olivera C, Jankovicb I, Comorb M and Vladimirova S 2006 J. Collo. Inter. Sci. 301692

Ortiz E, Vargas R and Mellander B 1999a J. Chem. Phys. 110 4847

Ortiz E, Vargas R and Mellander B 1999b Solid State Ionics 125177

Otomo J, Minagawa N, Wen C, Eguchi K and Takahashi H 2003 Solid State Ionic 156357

Rashkovich L N 1991 KDP-family single crystals (IOP Publishing)

Rietveld H M 1969 Acta Crystall. 265

Romain F and Novak A 1991 J. Mol. Struct. 26369

Ross Boyle 2005 Thermo fisher scientific (Madison WI, USA)

Toupry N and Poulet H 1981 Postollec MLe J Raman Spect. 1181 